\title{
Educação Empreendedora na Base da Inovação: análise de um Case de sucesso no empreendedorismo catarinense de base universitária
}

\author{
Entrepreneurial Education on the Basis of Innovation: a Case study of \\ success on university based entrepreneurship in Santa Catarina State
}

\author{
Illyushin Zaak Saraiva ${ }^{1}$ \\ Eduardo Butzen ${ }^{1}$ \\ Camilo Freddy Mendoza Morejon ${ }^{2}$ \\ ${ }^{1}$ Instituto Federal Catarinense, Luzerna, SC, Brasil \\ ${ }^{2}$ Universidade Estadual do Oeste do Paraná, Toledo, PR, Brasil
}

\begin{abstract}
Resumo
A Educação Empreendedora pode ser entendida como uma metodologia educacional voltada a desenvolver competências individuais relacionadas à geração de valor para a comunidade e à competência em inovar e agir de forma autônoma, buscando a sustentabilidade, e a literatura brasileira e estrangeira apresenta exemplos de atividades educacionais nas quais foi possível despertar em estudantes de diversos níveis características típicas do empreendedor, como agente promotor do empreendedorismo. Este trabalho exploratório e descritivo busca identificar possíveis elos entre a adoção de Atividades Educacionais de Formação em Empreendedorismo (AEFEs) em turmas da disciplina Empreendedorismo em cursos de Bacharelado em Engenharia, em um campus de um Instituto Federal do Estado de Santa Catarina, e os resultados obtidos pelos alunos em concursos e competições de ideias de negócio organizados pelo Sebrae-SC e pelo Governo Estadual. Resultados mostram correlação entre o número de alunos inscritos em concursos e o número de trabalhos classificados, concluindo-se ser positiva a metodologia adotada na disciplina.
\end{abstract}

Palavras-chave: Educação Empreendedora. Atividades Educacionais de Formação em Empreendedorismo. Concurso de Plano de Negócios.

\begin{abstract}
Entrepreneurial Education can be understood as an educational methodology aimed at developing individual competencies related to value creation for the community and the competence to innovate and act autonomously, seeking sustainability, and both Brazilian and international literatures present examples of successful educational activities, in which it was possible to awaken in students of various levels typical characteristics of the entrepreneur, as a promoter of entrepreneurship. This exploratory and descriptive work seeks to identify possible links between the adoption of Entrepreneurship Education Activities, AEFE's, for undergraduate Engineering courses on a campus of a Federal Institute in Santa Catarina State, Brazil, and the results obtained by students in business ideas competitions ran by Sebrae agency for microbusinesses and the State Government. Results show a correlation between the number of students enrolled in competitions and number of classified works, concluding that the methodology adopted on the discipline is positive.
\end{abstract}

Keywords: Entrepreneurial Education. Educational Training Activities in Entrepreneurship. Business Plan Competition. Área Tecnológica: Empreendedorismo. Economia do Conhecimento. 


\section{Introdução}

País com histórica tendência à burocratização e ao estabelecimento de excessiva formalidade para a abertura de novos empreendimentos econômicos, situando-se apenas na $53^{a}$ posição no que diz respeito à facilidade de formalização de novas empresas (SCHWINGEL; RIZZA, 2013), o Brasil apresenta por outro lado indicadores extremamente positivos no que tange ao empreendedorismo, sendo considerado um dos países mais empreendedores quando comparado aos membros da OCDE devido ao elevado número de cidadãos brasileiros que iniciam todo ano uma nova empresa e, por essa mesma razão, recentemente avaliado pelo indicador britânico Approved Index como o terceiro país mais empreendedor do mundo (APPROVED INDEX, 2015), enquanto uma pesquisa de mercado ainda mais recente da norte-americana Expert Market coloca o Brasil em $5^{\circ}$ lugar entre os países mais empreendedores (DISHMAN, 2017).

Embora a literatura aponte diferenças importantes entre o perfil médio do empreendedor brasileiro e o da média dos países da OCDE no que diz respeito à motivação para empreender - isto é, segundo o critério Oportunidade versus Necessidade do Global Entrepreunership Monitor - com o Brasil tendo um elevado percentual de empreendedores por necessidade (SEBRAE-SP, 2008), também chamados de viradores em referência ao ato de "se virar" (SOUZA NETO, 2008) - índice similar aos vivenciados em momentos de crise nas economias avançadas (FAIRLIE; FOSSEN, 2017), os estudos do Sebrae acerca das razões para o fechamento prematuro das micro e pequenas empresas apontam sistematicamente para a falta de planejamento prévio do negócio - sem a presença de quaisquer planos para itens gerenciais básicos antes da abertura da empresa - e a falta de conhecimento em administração de negócios - sem noções básicas sobre gestão financeira e necessidade de controle de fluxo de caixa, por exemplo (SEBRAE-SP, 2014; 2008).

Paralelamente, graças à atuação de universidades e órgãos técnicos de fomento e de assessoria ao pequeno empreendedor - tendo como exemplo mais importante o Serviço Brasileiro de Apoio às Micro e Pequenas Empresas, SEBRAE - tem havido desde os anos 1990 no Brasil um esforço de estímulo e de educação para o empreendedorismo em suas diversas modalidades (PACHECO et al., 2006), com dezenas de milhares de universitários tendo tido contato com disciplinas relacionadas ao empreendedorismo e à criação de planos de negócio, além de palestras e simpósios voltados à disseminação da cultura empreendedora, esforço que já ocorria de forma embrionária a partir da última década do século XX e que, a partir da década de 2000, ocorre de maneira robusta, com a realização de competições e concursos de ideias inovadoras e planos de negócio por todo o país, tendo como resultado a implantação de dezenas de parques tecnológicos e incubadoras de empresas, notadamente no Sul e Sudeste e em metrópoles do Nordeste do Brasil.

Esse esforço educacional brasileiro acompanha estímulo similar empreendido pelos Estados Unidos e nações Europeias também desde os anos de 1990. Segundo Blenker et al. (2008), tem havido no período forte pressão política sobre as universidades de Inglaterra, Suécia, Alemanha e Dinamarca no sentido de transformar-se a cultura, a sociedade e a própria educação superior, de formadoras de recebedores de salário em formadoras de empreendedores, pressão que teve resultados razoáveis levando-se em consideração que essa tendência em prol da colaboração entre atores externos e universidades para a consolidação da Educação Empreendedora é relativamente nova, e precisa superar a tendência antes vigente nesses países, a de professores 
agindo de forma individual, sem padronização de métodos ou objetivos no ensino do empreendedorismo (BLENKER et al., 2008).

Nos Estados Unidos, o número e a diversidade de cursos de graduação plena, para os quais as disciplinas de Empreendedorismo e Gestão de Pequenos Negócios passaram a ser oferecidas, têm crescido exponencialmente desde 1990, sendo esse crescimento estimulado em boa parte a partir da insatisfação dos alunos de graduação com o foco tradicional 'Fortune 500' - isto é, foco em vida profissional vinculada à empregabilidade em grandes corporações - que estava presente nas disciplinas da área de administração até então ofertadas (GWU, 2015).

Dolabela e Filion (2014) postulam que a educação empreendedora seja uma das ferramentas mais poderosas para desenvolver numa determinada sociedade o espírito do empreendedorismo - entendido por tais autores como uma cultura, que se manifesta em certo tipo de pensamento e ação - por meio de programas educacionais para o empreendedorismo em todos os níveis de ensino, desde as séries fundamentais até o nível superior.

Nesse sentido, argumenta-se que a prática da educação empreendedora, cuja definição genérica aqui adotada é a do conjunto de metodologias educacionais voltadas a desenvolver competências individuais relacionadas à geração de valor para a comunidade e à competência em inovar, e em agir de forma autônoma e crítica, buscando a sustentabilidade (PACHECO et al., 2006), embora não necessariamente provoque como resultado direto a abertura de novas empresas pelos alunos, certamente provocará mudanças paradigmáticas nos estudantes em termos de visualização de mudanças da estrutura econômica, e de identificação de oportunidades de negócio, para além das competências gerenciais porventura incluídas nos programas e currículos adotados. Segundo Lima et al. (2014), a educação empreendedora, quando presente em alta qualidade durante um curso superior, muda valores e aperfeiçoa capacidades, especialmente a capacidade de inovação, a criatividade e a tomada de iniciativa, qualidades essenciais aos que se propõem liderar processos de mudança e, mesmo, iniciar novos empreendimentos econômicos (LIMA et al., 2014).

Ainda nesse ínterim, exemplos de atividades e projetos educacionais de sucesso (BECKER; SEVERO; GUIMARÃES, 2017) têm sido apresentados na literatura recente em Educação Empreendedora, pelos quais foi possível verificar em estudantes de diversos níveis o despertar de algumas características típicas do empreendedor (GARCIA et al., 2013) aqui definido como o agente econômico promotor do empreendedorismo, sendo que alguns trabalhos lograram verificar a influência desse processo e da utilização das chamadas Atividades Educacionais de Formação em Empreendedorismo (AEFEs) - denominação que incorpora ações diversas como estudos de caso, palestras na área, visitas técnicas a empresas, brainstorming entre os alunos, simulações de empresas, leituras específicas, etc. (ROCHA; FREITAS, 2014) - sobre o interesse e/ou aprendizado dos alunos, incluindo o estudo Guesss Brasil 2013/2014, para o qual atividades diversificadas, maior número de disciplinas voltadas à área, proximidade com startups e incubadoras e com a realidade dos empreendedores, aumentam em grande medida a atenção e interesse dos estudantes de cursos superiores (LIMA et al., 2014).

Este trabalho, que não tem a pretensão de analisar de forma direta possíveis mudanças de paradigma provocadas em estudantes, seja por entrevista em profundidade ou questionários, nem por meio de quaisquer outros métodos existentes, por se tratar de tarefa complexa que exigiria provavelmente dados indisponíveis no curto prazo, dada a necessária realização de pesquisa de opinião (Survey) com os estudantes (ROCHA; FREITAS, 2014), propõe-se apenas 
investigar possíveis correlações entre a realização de AEFEs em cursos superiores e a capacidade dos estudantes em ter suas ideias ou planos de negócio aprovados em processos de avaliação e seleção externas.

É objetivo deste estudo, portanto, analisar quantitativamente a relação entre a oferta da educação formal em empreendedorismo para alunos de engenharia no Campus Luzerna do Instituto Federal Catarinense, e o desempenho desses estudantes em concursos, premiações e outros certames de empreendedorismo disputados, como o Concurso do Sebrae-SC e o Edital Sinapse da Inovação do Governo Catarinense realizando-se comparações de ordem quantitativa e produzindo conjuntos de dados e informações que permitam futuras análises aprofundadas sobre os resultados da educação empreendedora dentro do recorte geográfico e temporal analisado.

O artigo é composto de cinco seções, sendo elas esta introdução, a metodologia, os resultados, as considerações finais e as referências.

\section{Metodologia}

O intervalo de observação analisado neste trabalho diz respeito ao período entre o segundo semestre de 2014 e o primeiro semestre de 2018, delimitado pelos meses de agosto de 2014 e agosto de 2018, sendo analisados dados quantitativos referentes ao número de alunos dos cursos de Engenharia do campus analisado matriculados na disciplina Empreendedorismo, ao número desses estudantes com trabalhos inscritos em concursos estaduais de planos e ideias de negócio, e também ao número de alunos cujo plano de negócio foi aprovado para hospedagem na Incubadora Tecnológica Municipal, que está situada a 200 metros do campus analisado e com ele mantém grande interação.

A escolha do intervalo descrito se dá especificamente por duas razões de fundo: em primeiro lugar, em razão da disciplina Empreendedorismo ter sido oferecida pela $1^{\mathrm{a}}$ vez aos alunos de graduação do referido campus no ano de 2015 e, portanto, o concurso de Planos de Negócio do Sebrae-SC imediatamente anterior ao início da oferta da matéria ter sido exatamente aquele realizado no segundo semestre de 2014. Em segundo lugar, por ter sido o concurso do Sebrae-SC do primeiro semestre de 2018 o mais recente concurso estadual já completo e finalizado.

Outra delimitação diz respeito ao tipo de classificação dos alunos nos concursos estaduais. No que diz respeito ao concurso do Sebrae-SC, são aqui considerados como "classificados" todos os alunos que ascenderam à segunda fase do concurso, não necessariamente tendo chegado à etapa final. Acerca do edital Sinapse da Inovação, contudo, são apenas considerados os alunos vendedores do concurso.

Dessa forma, tomando-se como unidade básica de análise cada semestre letivo com a oferta de empreendedorismo, no intervalo de seis semestres observado, observa-se a ocorrência dos seguintes casos especiais: (a) semestres em que a disciplina não foi oferecida e houve pelo menos um concurso estadual; (b) semestres em que a disciplina foi oferecida, mas não houve concursos estaduais; (c) semestres em que a disciplina foi oferecida e houve pelo menos um concurso estadual; sendo tais alternativas úteis na verificação de possíveis influências da disciplina como estímulo ao empreendedorismo de base universitária dentro do universo analisado, 
através da utilização da variável "ter cursado ou estar cursando a disciplina empreendedorismo" como controle.

Os dados quantitativos aqui analisados são todos secundários, obtidos por meio de pesquisa documental (QUIVY; CAMPENHOUDT, 2008), com foco especial nos registros digitais da disciplina Empreendedorismo disponíveis no sistema SIGA da instituição analisada (IFC, 2018), nas listagens de trabalhos inscritos e trabalhos premiados dos concursos Sebrae-SC (2014; 2015; 2016; 2017; 2018) e Sinapse da Inovação (2015; 2017) disponíveis nos respectivos websites, além das listagens de empresas incubadas na Incubadora Tecnológica Municipal de Luzerna, cidade analisada (ITL, 2019).

As listas e tabelas foram convertidas para formato MS-Excel 2013, tratando-se os dados de acordo com as análises adequadas aos objetivos, compondo tabelas e gráficos, conforme o tipo de variável.

\section{Resultados e Discussão}

O campus analisado, localizado no Município de Luzerna, teve sua origem em 2010, a partir da incorporação pela União de uma antiga fundação de educação tecnológica que funcionava no mesmo local, sendo o prédio original da fundação atualmente reservado às aulas dos cursos de Engenharia Mecânica (EMA), e Engenharia de Controle e Automação (ECA). Após a federalização, a escola foi imediatamente incorporada ao IFC, um dos dois Institutos Federais de Educação Ciência e Tecnologia criados em Santa Catarina em 2008 a partir da fusão de Escolas Agrotécnicas e Colégios Técnicos de universidades federais.

A graduação em Engenharia de Controle e Automação, bacharelado, iniciou no segundo semestre de 2011, sendo a Engenharia Mecânica mais recente, iniciada apenas no primeiro semestre de 2014. Atualmente, funcionam além dos dois cursos de Engenharia, três cursos técnicos: em Mecânica, nas modalidades integrado ao médio e subsequente; em Segurança do Trabalho, apenas na modalidade integrado ao médio; e Automação Industrial, também ofertado nas duas modalidades, perfazendo em junho de 2019 um total de 440 alunos de Engenharia e 270 de cursos técnicos (IFC, 2019).

Um dos diferenciais do referido campus em relação aos demais é sua localização, situado na pequena cidade de Luzerna, SC, com apenas 5.686 habitantes (IBGE, 2019) que ostenta indicadores de destaque, como o $71^{\circ} \mathrm{IDH}$ Municipal mais elevado entre 5.565 municípios brasileiros, da ordem de 0,789 e um IDEB ( $8^{\mathrm{a}}$ série/ $9^{\circ}$ ano) de 6,1 em 2017, um dos 30 mais elevados do Estado de Santa Catarina (INEP, 2018). Contudo, a característica local mais importante trata da composição do seu PIB municipal, ocupando o setor metalomecânico a primeira posição em termos de Valor Adicionado Fiscal, VAF (SEBRAE-SC, 2013). Desde sua criação em 2010, os alunos do campus realizaram estágios em dezenas de indústrias metalúrgicas e mecânicas do município, e em mais de uma centena de empresas da microrregião de abrangência (LACERDA et al., 2018).

Em 2015, houve a oferta da primeira turma da disciplina Empreendedorismo como matéria obrigatória aos alunos dos cursos de Engenharia, sem pré-requisitos, obtendo-se naquele momento apenas 10 alunos inscritos na matéria. Foi nesse momento que a coordenação da disciplina, em conjunto com a Direção Geral do campus, adotou como estratégia a participação 
dos alunos no Concurso Sebrae-SC de Planos de Negócio para Universitários, edição 2015, que tinha como prazo para submissão dos planos o final do mês de novembro.

Os alunos também participaram de uma visita à Incubadora Tecnológica Municipal, que funciona a cerca de 200 metros do campus e tinha edital de incubação aberto, e foram estimulados a enviar ideias de negócio para o Concurso Sinapse da Inovação, promovido pelo Estado de Santa Catarina e que premiaria cada um dos vencedores com $\mathrm{R} \$ 60$ mil em recursos para a criação de uma empresa.

O diagrama da Figura 1 a seguir apresenta a linha do tempo simplificada dos fatos analisados.

Figura 1 - Principais momentos na evolução do ensino de Empreendedorismo no Campus Luzerna

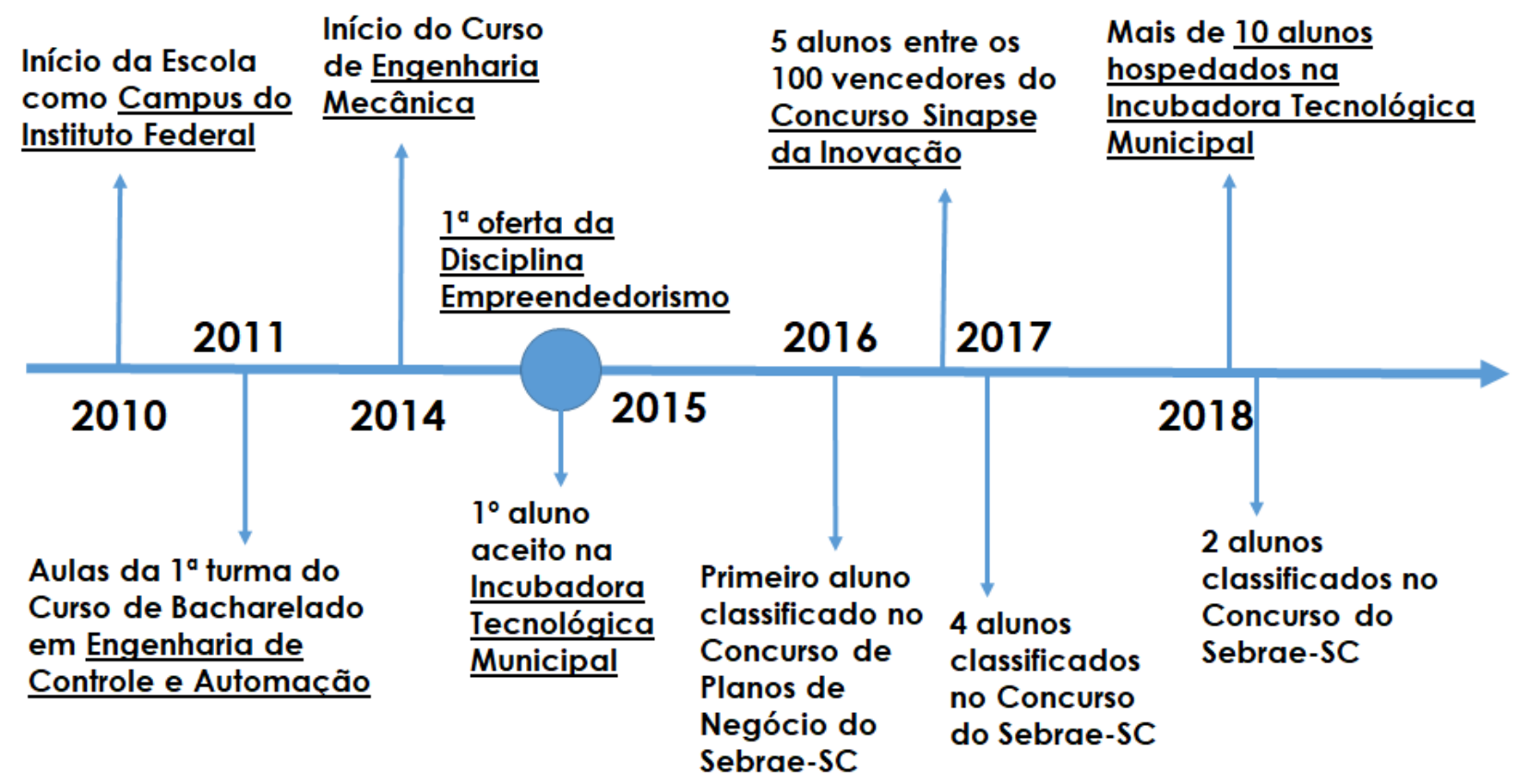

Fonte: Elaborada pelos autores deste artigo

Como se observa no diagrama da Figura 1, já em 2015 o campus Luzerna obtém o que pode ser considerado como primeiro resultado efetivo da nova metodologia adotada, com a aprovação do primeiro aluno da disciplina Empreendedorismo a iniciar uma startup na Incubadora Tecnológica Municipal.

Nos anos seguintes, a submissão de ideias de negócio ao Concurso do Sebrae-SC tornou-se um dos motivadores principais da disciplina, estabelecendo-se em cada semestre um cronograma de atividades preparatórias para a elaboração das ideias - a partir de 2016 o Concurso do Sebrae-SC mudou, não aceitando mais planos de negócio, e sim ideias de negócio, mais resumidas e sem a possibilidade de inserção de figuras ou tabelas, permitindo-se apenas texto - incluindo-se no programa da disciplina a realização de palestras específicas, cursos de elaboração de pitchs e ideias de negócio, além de treinamento na operação do software Plano de Negócio 3.0® fornecido gratuitamente pelo Sebrae-MG.

Com a finalidade de analisar-se de forma minuciosa os resultados efetivos dos estudantes da disciplina Empreendedorismo, categoriza-se aqui dois tipos de conquistas, sendo em primeiro lugar as aprovações para hospedagem de startups na Incubadora Municipal, que envolve a criação de uma empresa real mas cuja concorrência é relativamente baixa, e em segundo 
lugar a classificação de sua ideia de negócio em concursos estaduais, sejam eles o Concurso Sebrae-SC ou o Concurso Sinapse da Inovação, que não necessariamente envolvem a criação de uma empresa real - embora provavelmente levem à fundação de uma empresa - cuja concorrência é elevadíssima.

O gráfico da Figura 2 traz um comparativo entre o número de alunos matriculados na disciplina empreendedorismo por cada semestre, além do número de alunos que submeteram ideias ou planos de negócio em concursos estaduais no semestre, e os classificados nesses concursos.

Figura 2 - Evolução da disciplina Empreendedorismo por semestre

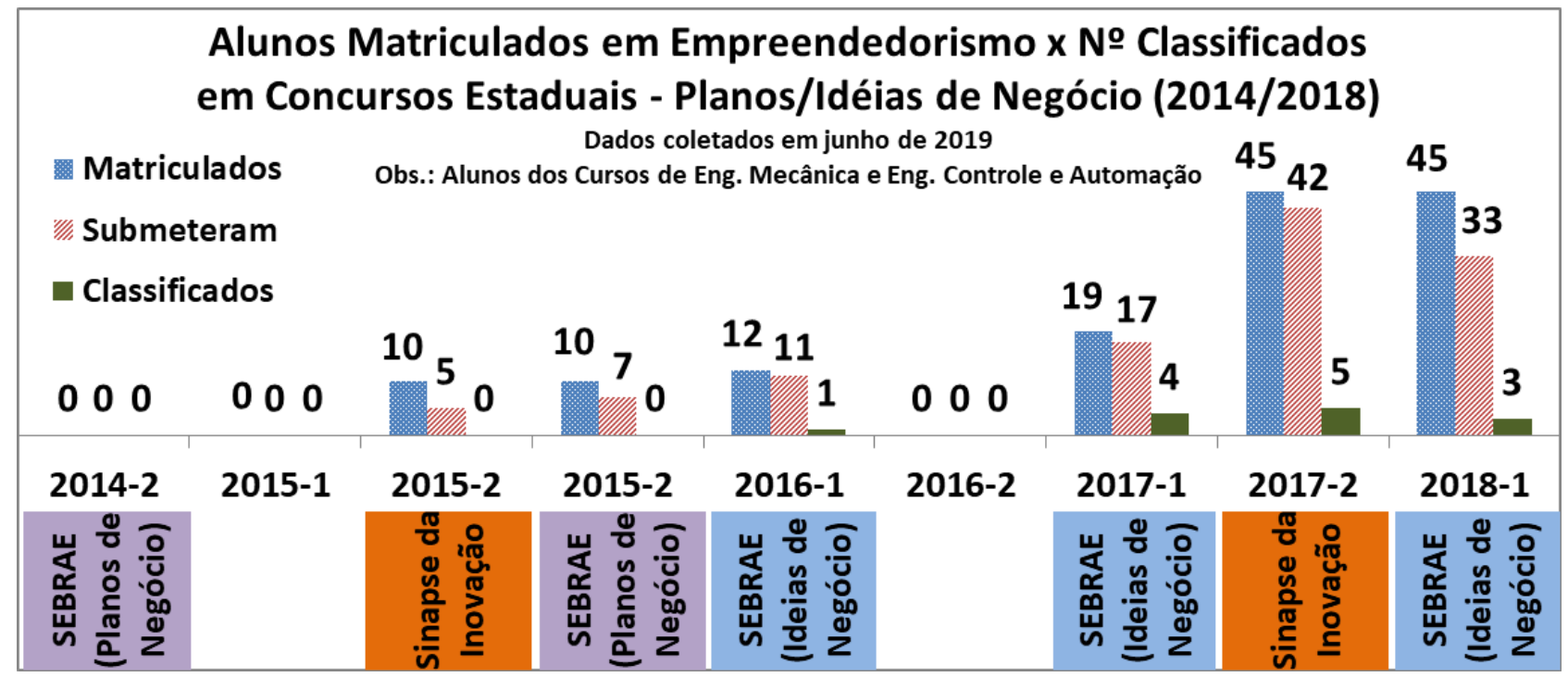

Fonte: Elaborada pelos autores deste artigo com dados de Sebrae (2014; 2015; 2016; 2017; 2018); Sinapse da Inovação $(2015 ; 2017)$ e dados do sistema SIGA do Instituto Federal Catarinense (IFC, 2018)

Os quadros no eixo horizontal são os semestres analisados, e observa-se que não houve oferta da disciplina Empreendedorismo no segundo semestre de 2014, no primeiro semestre de 2015 no segundo semestre de 2016, embora nenhum dos dois concursos estaduais, isto é, o Concurso Sebrae-SC e a Sinapse da Inovação, exija ou exigisse a matrícula nesta disciplina como pré-requisito para inscrição.

Contudo, no que diz respeito aos inscritos, é possível verificar-se que não houve alunos inscritos na edição 2014 do Concurso Sebrae-SC, embora àquela altura o campus já tivesse cerca de 200 alunos de Engenharia, aptos a participarem do concurso, que permite apenas a inscrição de universitários.

Se em 2014 não houve inscritos, a observação do gráfico acima sugere uma pequena correlação - que até poderia ser esperada - entre o número de alunos inscritos no concurso, expresso na coluna com hachura azul clara, e o número de alunos classificados, expressos na última coluna à direita de cada semestre, em verde escuro. Com efeito, o semestre em que o maior número de alunos saiu vencedor, 2017-2, foi justamente aquele em que o maior número de alunos fez inscrição.

Dessa forma, passou-se ao estudo da correlação entre as variáveis número de Alunos Inscritos versus número de Alunos Classificados, e também entre a segunda e o número de alunos Matriculados, exposto na Figura 3. 
Figura 3 - Correlação entre o número de alunos que submeteram negócios e o número de alunos classificados

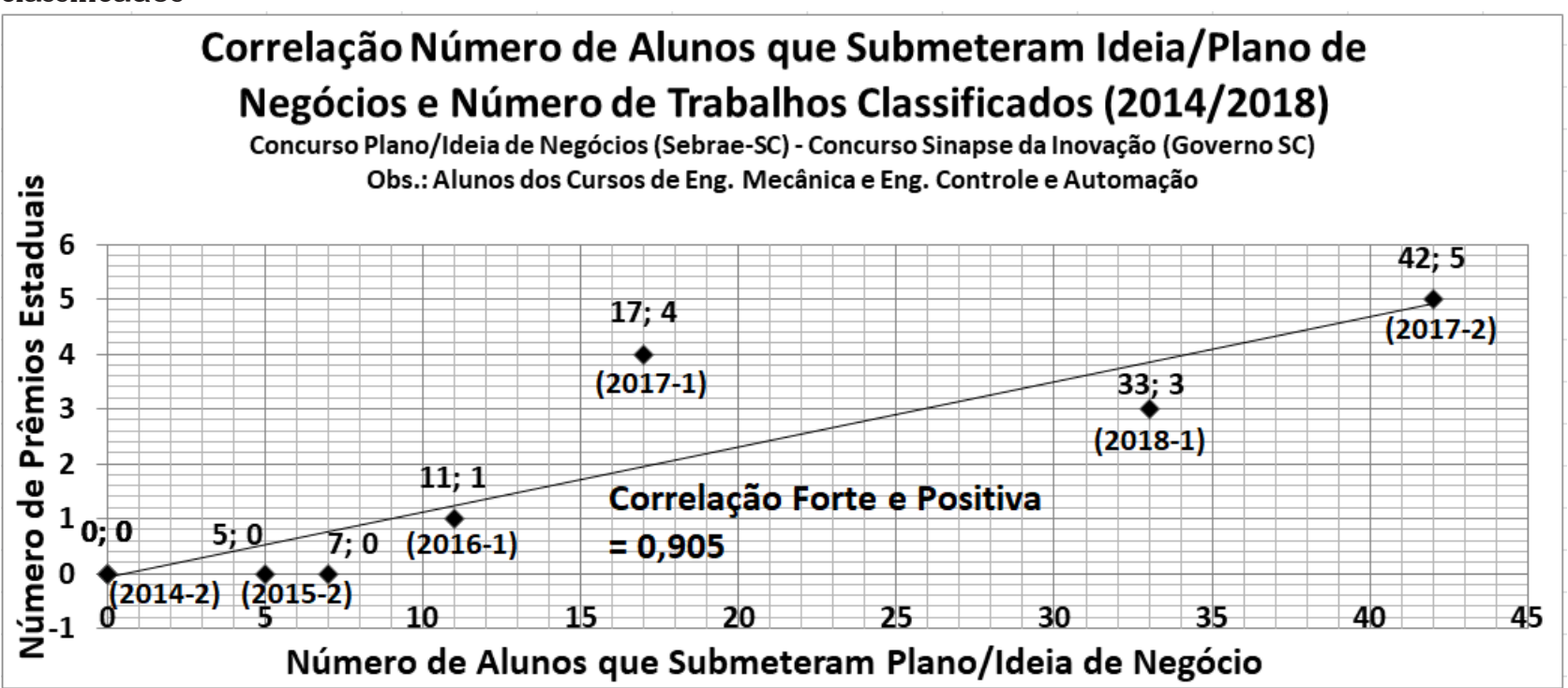

Fonte: Elaborado pelos autores com dados de Sebrae (2014; 2015; 2016; 2017; 2018); Sinapse da Inovação $(2015 ; 2017)$

Como se nota na Figura 3, a correlação observada entre as duas variáveis, número de Alunos que Submeteram Ideias/Planos de Negócio no Semestre versus número de Alunos Classificados em Concursos Estaduais, é de 0,905 forte e positiva, variando do pior resultado, que foi o segundo semestre de 2014, quando nenhum aluno submeteu plano de negócio e obviamente nenhum foi premiado, e o resultado mais importante, o segundo semestre de 2017, quando 42 submeteram e cinco foram classificados.

O gráfico da Figura 2 sugere também correlação entre o número de alunos matriculados na disciplina e o número de alunos que submeteram negócios, correlação esta compreensível dada a metodologia adotada na disciplina a partir de sua criação em 2015, quando um dos objetivos dos estudantes passou a ser justamente o aprendizado amplo sobre a identificação $e$ elaboração de ideias de negócio, correlação esta apresentada no gráfico da Figura 4 a seguir.

Figura 4 - Correlação entre o número de alunos matriculados no semestre e o número dos que submeteram negócios

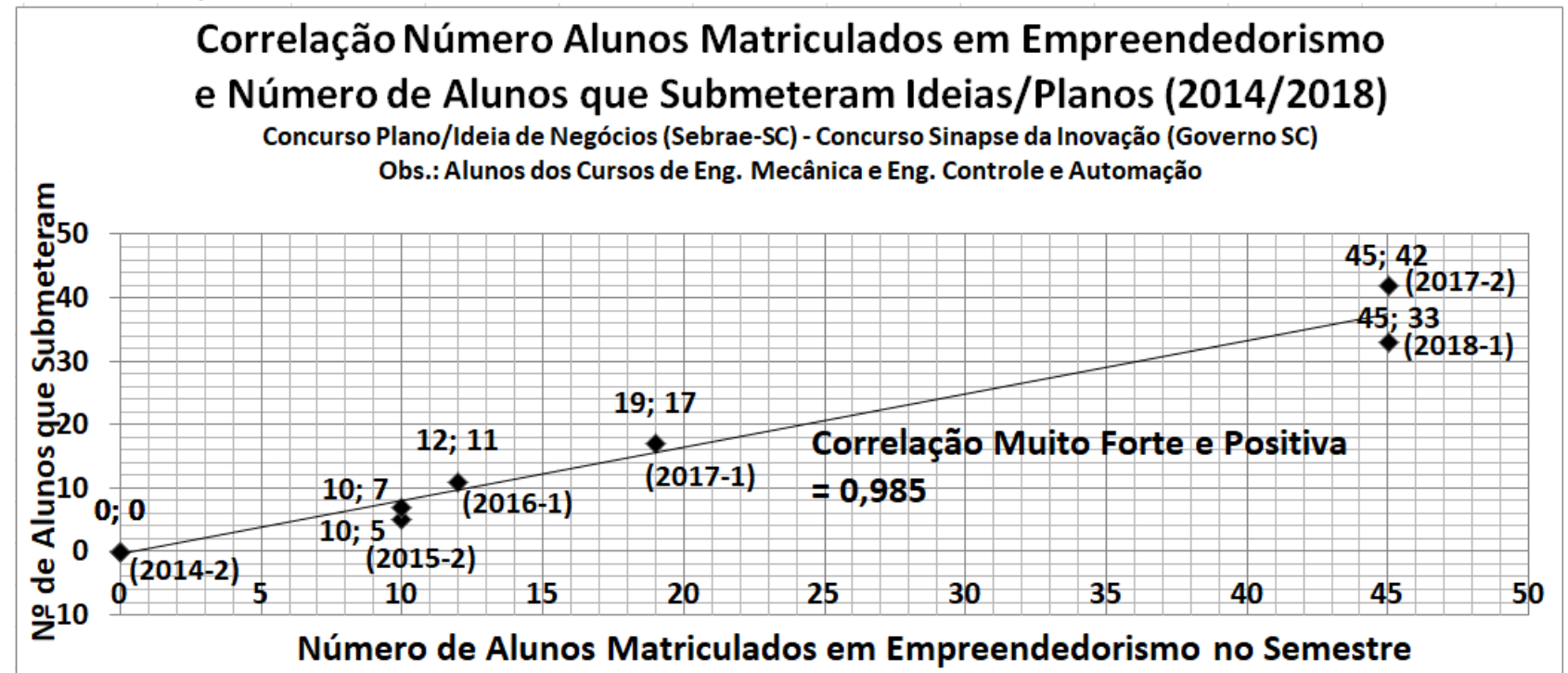

Fonte: Elaborado pelos autores com dados de Sebrae (2014; 2015; 2016; 2017; 2018); Sinapse da Inovação $(2015 ; 2017)$ e dados do sistema SIGA do Instituto Federal aqui analisado 
Vê-se na Figura 4 a correlação entre número de Alunos Matriculados no semestre versus o número de Alunos que Submeteram Ideias/Planos de Negócio, ainda mais forte e positiva que a anterior, da ordem de 0,985 e, por isso mesmo, considera-se de grande importância constatar que, ainda que o número de alunos matriculados não possa ser diretamente associado de forma causal ao número premiações ou classificações obtidas em avaliações externas pelos planos/ideias de negócios dos alunos, o gráfico da Figura 2 demonstrou que há correção entre o número de Submissões e o número de Premiações e, por outro lado, constata-se aqui que há correlação entre Matrículas e Submissões, de onde se concluir ser de grande importância a metodologia adotada, que coloca na elaboração de uma boa ideia ou plano de negócio a centralidade dos esforços de alunos e professores na construção do conhecimento.

O gráfico da Figura 5 apresenta ainda o teste de outra correlação possível, aquela entre o número de Matriculados por semestre e o número de Alunos Classificados (ou premiados).

Figura 5 - Correlação entre número de alunos matriculados no semestre e número de ideias classificadas

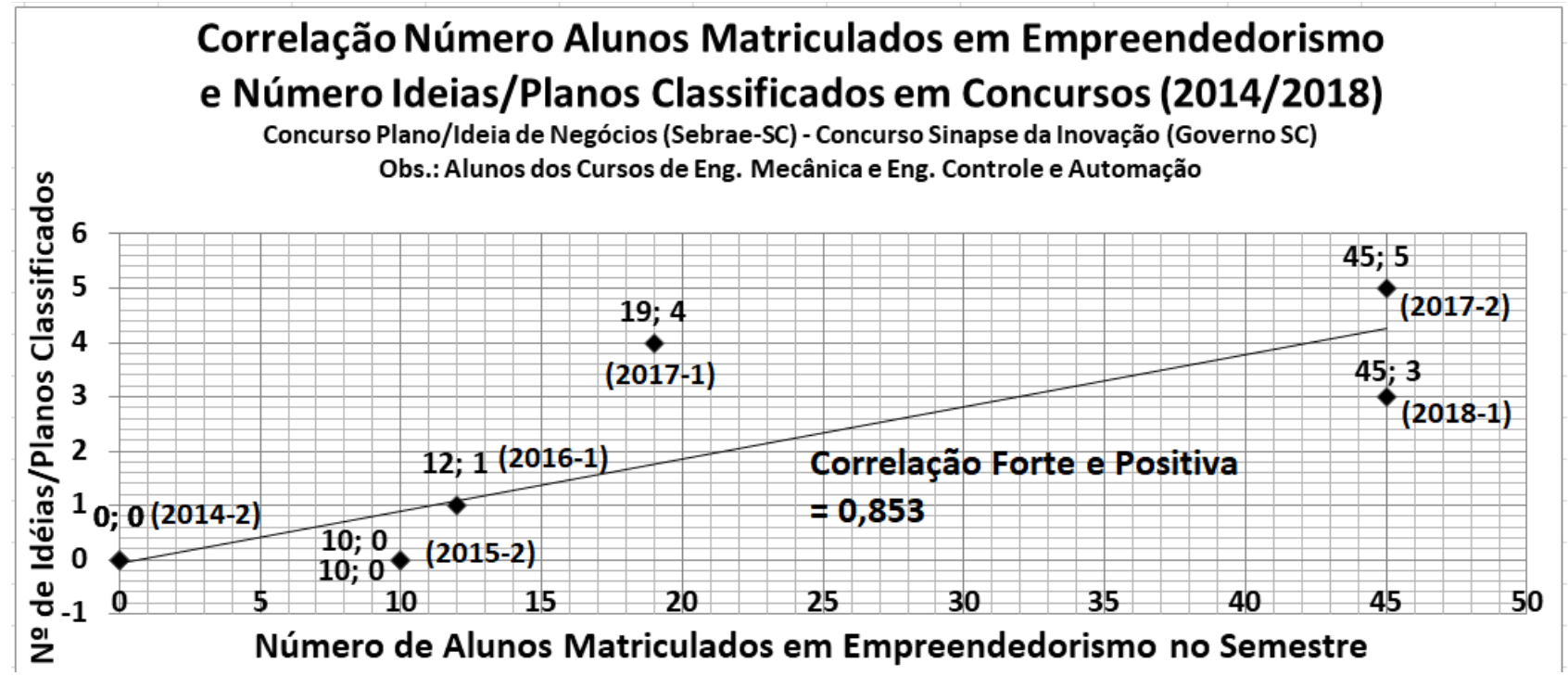

Fonte: Elaborado pelos autores com dados de Sebrae (2014; 2015; 2016; 2017; 2018); Sinapse da Inovação $(2015 ; 2017)$ e dados do sistema SIGA do Instituto Federal aqui analisado

Como se vê no Gráfico da Figura 5, a correlação entre o número de Alunos Matriculados por Semestre e o número de trabalhos classificados em certames externos, tem valor menor que as anteriores, porém ainda positiva. Embora não seja possível, dentro do universo investigado e com as informações coletadas, identificar dimensões ou variáveis relacionadas à opinião dos alunos, infere-se que o maior número de alunos cursando a disciplina Empreendedorismo sob a metodologia adotada, presumivelmente pode levar a um maior número de trabalhos classificados em certames estaduais.

Finalmente, analisando o conjunto dos gráficos expostos neste trabalho, referentes à participação de alunos da disciplina Empreendedorismo dos Cursos de Engenharia do campus analisado neste trabalho, pode-se inferir que a metodologia adotada na disciplina, com enfoque na elaboração de ideias ou planos de negócio competitivos e sua submissão a concursos externos, através da centralidade dos esforços de alunos e professores envolvidos, apresenta resultados satisfatórios em termos das conquistas alcançadas ao longo do período analisado. 
Importante frisar que, devido ao fato de que todas as turmas da disciplina estiveram submetidas à mesma metodologia, não foi possível realizar análise comparativa entre a adoção ou não do método e sua influência em termos de classificação em concursos (premiação).

\section{Considerações Finais}

Chega-se neste momento à conclusão de que o referido campus inovou ao adotar metodologia de vanguarda em Educação Empreendedora, preparando os alunos na teoria e na prática para a construção de ideias de negócio com tal qualidade que eles foram capazes de obter classificações em prêmios estaduais, como o Concurso Sebrae-SC de Negócios Inovadores, que premia as melhores ideias com tablets e viagens ao Vale do Silício, ou como o programa Sinapse da Inovação, mantido pela Fapesc e que premia a cada dois anos as 100 melhores ideias de negócio submetidas por milhares de empreendedores e inventores individuais com $\mathrm{R} \$ 100$ mil em recursos para cada um dos vencedores, além de oferecer treinamento e mentoria a eles.

Observa-se assim, no que diz respeito ao objetivo principal deste trabalho, que apesar do pouco alcance de análise possibilitado pelos dados disponíveis, que a metodologia adotada na educação formal em empreendedorismo oferecida aos alunos de engenharia do campus analisado aparenta ter efeito positivo sobre o desempenho desses estudantes nos concursos e premiações informados no trabalho, havendo correlação positiva entre o número de alunos matriculados em cada turma da disciplina e o número de alunos classificados nestes concursos.

Finalmente, considera-se que o objetivo deste trabalho foi cumprido, na medida em que além de verificado o efeito da metodologia de ensino analisada sobre o desempenho dos alunos, também foram produzidos gráficos que podem servir de fonte para investigações mais amplas e de maior base geográfica, que procurem analisar o quadro regional ou nacional da educação empreendedora, e é desejo dos autores que trabalhos similares possam ser realizados por professores engajados no ensino do empreendedorismo em instituições semelhantes.

\section{Referências}

APPROVED INDEX. Map: Entrepreneurship Around the World. The Approved Index Blog. 25 jun. 2015. Disponível em: https://blog.approvedindex.co.uk/2015/06/25/map-entrepreneurshiparound-the-world/. Acesso em: 22 jul. 2019.

BECKER, Alessandro; SEVERO, Eliana A.; GUIMARÃES, Julio C. Ferro. Empreendedorismo e Inovação e sua Perspectiva com o Ensino. In: XVII MOSTRA DE INICIAÇÃO CIENTÍFICA, PósGraduação, Pesquisa e Extensão. Universidade de Caxias do Sul, nov. 2017. Anais [...]. Caxias do Sul, 2017.

BLENKER, Per et al. A framework for developing entrepreneurship education in a university context. International Journal of Entrepreneurship and Small Business, [S.l.], v. 5, n. 1, p. 45-63, 2008.

DISHMAN, Lydia. These Are the Countries With the Most Determined Entrepreneurs. $1^{\circ}$ jun. 2017. Disponível em: https:/www.fastcompany.com/3066997/these-are-the-countries-with-the-mostdetermined-entrepreneurs. Acesso em: 12 jun. 2019.

DOLABELA, Fernando; FILION, Louis Jacques. Fazendo Revolução no Brasil: a introdução da 
Pedagogia Empreendedora nos estágios iniciais da educação. Revista de Empreendedorismo e Gestão de Pequenas Empresas, [S.l.], v. 2, n. 3, p. 134-181, maio 2014.

FAIRLIE, Robert W.; FOSSEN, Frank M. Opportunity versus Necessity Entrepreneurship: Two Components of Business Creation. Stanford Institute for Economic Policy Research Discussion Paper n. 17-014, 27 abr. 2017. Disponível em: http://dx.doi.org/10.2139/ssrn.3010267. Acesso em: 29 jul. 2019.

GARCIA, Renato et al. Empreendedorismo Acadêmico no Brasil: Uma Avaliação da Propensão à Criação de Empresas por Estudantes Universitários. Revista de Empreendedorismo e Gestão de Pequenas Empresas, [S.I.], v. 1, n. 3, p. 36-63, jan. 2013.

GWU. The National Survey of Entrepreneurship Education: an Overview of 2012-2014 Survey Data. 2015. Disponível em: www.nationalsurvey.org/files/2014KauffmanReport_Clean.pdf. Acesso em: 12 maio 2019.

IBGE - INSTITUTO BRASILEIRO DE GEOGRAFIA E ESTATÍSTICA. Cidades. 2019. Disponível em: https://cidades.ibge.gov.br. Acesso em: 30 jul. 2019.

IFC - INSTITUTO FEDERAL CATARINENSE. Censo Interno. Maio 2019. Retificação. Disponível em: http://ifc.edu.br/wp-content/uploads/2014/08/Censo-Interno-MAIO-2019retifica\%C3\%A7\%C3\%A3o.pdf. Acesso em: 29 jul. 2019.

IFC - INSTITUTO FEDERAL CATARINENSE. Sistema Integrado de Gestão Acadêmica. 2018. Disponível em: https://sig.ifc.edu.br/sigaa/portais/docente/turmas.jsf. Acesso em: 25 jul. 2019.

INEP - INSTITUTO NACIONAL DE ESTUDOS E PESQUISAS. Resultados e Metas Ideb. 2018. Disponível em: http://www.ideb.inep.gov.br/resultado/. Acesso em: 30 jul. 2019.

ITL - INCUBADORA TECNOLÓGICA LUZERNA. Empresas Residentes na Incubadora Tecnológica de Luzerna e suas Áreas de Atuação. 2019. Disponível em: http://www. incubadoraluzerna.com.br/. Acesso em: 22 abr. 2019.

LACERDA, Matheus Souza et al. Extensão Tecnológica para Além do Social: O Ecossistema de Inovação do APL de Joaçaba e sua relação com o Campus Luzerna do IFC, um modelo para a Rede Federal? Micti, [S.l.], v. 8, n. 1, nov. 2018. Disponível em: https://doi.org/10.13140/ RG.2.2.21639.75689. Acesso em: 29 jul. 2019.

LIMA, Edmilson et al. Educação Superior em Empreendedorismo e Intenções Empreendedoras dos Estudantes - Relatório do Estudo GUESSS Brasil 2013-2014. Grupo APOE - Grupo de Estudo sobre Administração de Pequenas Organizações e Empreendedorismo, PPGA-UNINOVE. Caderno de Pesquisa, São Paulo: Grupo APOE, n. 2014-03, 2014.

PACHECO, Andressa S. V. et al. A Pedagogia de Paulo Freire e a Pedagogia Empreendedora. In: VI COLÓQUIO INTERNACIONAL SOBRE GESTÃO UNIVERSITÁRIA NA AMÉRICA DO SUL. Blumenau, 2006. Anais [...]. Blumenau, 2006.

QUIVY, R.; CAMPENHOUDT, L. V. Manual de investigação em ciências sociais. 5. ed. Lisboa: Gradiva. 2008.

ROCHA, Estevão Lima de Carvalho; FREITAS, Ana Augusta Ferreira. Avaliação do Ensino de Empreendedorismo entre Estudantes Universitários por meio do Perfil Empreendedor. Revista de Administração Contemporânea, [S.l.], v. 18, n. 4, p. 465-486, ago. 2014.

SCHWINGEL, Inês; RIZZA, Gabriel. Políticas Públicas para Formalização das Empresas: Lei geral 
das micro e pequenas empresas e iniciativas para a desburocratização. Mercado de Trabalho, [S.l.], v. 54, 2013. Repositório do Conhecimento do IPEA. Disponível em: repositorio.ipea.gov.br/ handle/11058/3846. Acesso em: 2 ago. 2019.

SEBRAE-SC. Listagem de Todos os Alunos Vinculados - 2018. Concurso de Negócios Inovadores. [2018]. Disponível em: ambiente.concurso.sebrae-sc.com.br/2018/teacher/my_students. Acesso em: 3 jun. 2019.

SEBRAE-SC. Listagem de Todos os seus Alunos Vinculados - 2014. Concurso de Negócios Inovadores. [2014]. Disponível em: http://ambiente.concursopn.sebrae-sc.com.br/professor/meusalunos. Acesso em: 18 jun. 2017.

SEBRAE-SC. Listagem de Todos os seus Alunos Vinculados - 2015. Concurso de Negócios Inovadores. [2015]. Disponível em: http://ambiente.concursopn.sebrae-sc.com.br/professor/meusalunos. Acesso em: 18 jun. 2017.

SEBRAE-SC. Listagem de Todos os seus Alunos Vinculados - 2016. Concurso de Negócios Inovadores. [2016]. Disponível em: http://ambiente.concursopn.sebrae-sc.com.br/professor/meusalunos. Acesso em: 18 jun. 2017.

SEBRAE-SC. Listagem de Todos os seus Alunos Vinculados - 2017. Concurso de Negócios Inovadores. [2017]. Disponível em: http://ambiente.concursopn.sebrae-sc.com.br/professor/meusalunos. Acesso em: 18 jun. 2017.

SEBRAE-SC. Santa Catarina em Números: Santa Catarina. Florianópolis: SEBRAE-SC, 2013. $150 \mathrm{p}$.

SEBRAE-SP. 10 nos de Monitoramento da Sobrevivência e Mortalidade de Empresas. ISBN: 978-85-7376-069-9. São Paulo: SEBRAE-SP, 2008. 120p.

SEBRAE-SP. Causa Mortis: o sucesso e o fracasso das empresas nos primeiros 5 anos de vida. jul. 2014. Apresentação em formato PDF. Disponível em: http://www.sebrae.com.br/Sebrae/Portal\%20 Sebrae/UFs/SP/Anexos/causa_mortis_2014.pdf. Acesso em: 3 jun. 2019.

SINAPSE DA INOVAÇÃO. Conheça as Empresas Criadas na Op.SC.VI. 2017. Disponível em: http://www.sc6.sinapsedainovacao.com.br. Acesso em: 15 ago. 2019.

SINAPSE DA INOVAÇÃO. Conheça as Empresas Criadas na Op-SC-V. 2015. Disponível em: http://www.sc5.sinapsedainovacao.com.br. Acesso em: 9 ago. 2019.

SOUZA NETO, Bezamat. Contribuição e Elementos para um Metamodelo Empreendedor Brasileiro: o empreendedorismo de necessidade do "virador". 1. ed. São Paulo: Blucher, 2008.

\section{Sobre os Autores}

\section{Illyushin Zaak Saraiva}

E-mail: illyushin.saraiva@ifc.edu.br

Especialista em Educação Empreendedora (UFSJ, 2014).

Endereço Profissional: Rua Vigário Frei João, n. 550, Centro, Luzerna, SC. CEP: 89.609-000. 


\section{Eduardo Butzen}

E-mail: eduardo.butzen@ifc.edu.br Especialista em Automação e Sistemas (UFSC, 2004).

Endereço profissional: Rua Vigário Frei João, n. 550, Centro, Luzerna, SC. CEP: 89.609-000.

\section{Camilo Freddy Mendoza Morejon}

E-mail: camilo_freddy@hotmail.com

Doutor em Engenharia Mecânica (UFRJ, 2003).

Endereço profissional: Rua da Faculdade, n. 645, Jardim La Salle, Toledo, PR. CEP: 85903-000. 